compared with $25 \%)$ problems $(P=0.07)$. Analysis of detailed problems shows significantly more social relations problems among section referrals $(65 \%)$ than other referrals $(41 \%)(P=0.02)$. The practitioners were asked to indicate which from the range of psychiatric and social problems they considered to be primary. Section referrals showed greater emphasis on mental health and psychosis: $60 \%$ were considered to be primarily psychotic, $15 \%$ neurotic and $18 \%$ emotional or relationship. Other referrals were considered primarily psychotic in $11 \%$ of cases, and neurotic and to have emotional or relationship primary problems in, respectively, $34 \%$ and $41 \%$ of referrals $(P<0.0001)$.

Intervention was quite different for the two groups. Those not referred for section assessment received significantly more information and advice, psychodynamic therapy and discussion of future options. Very few were subject to section assessment, and always after the initial referral. Non section referrals were also subject to significantly longer intervention: one was seen for more than a week, compared with $32 \%$ of other referrals $(P<0.005)$. Only $12 \%$ of section referrals compared with $34 \%$ of other referrals were subject to more than two interviews $(P<0.0004)$. A high proportion of other referrals nonetheless received brief intervention, reflecting the gatekeeping role of the service, whereby patients were referred for assessment or advice by other professionals, or where they were subsequently referred on to other agencies considered appropriate for their needs.

\section{Comment}

Although the number of section referrals studied here was relatively small, these data are nonetheless useful. There is generally a lack of information on GP section referrals, as there is great difficulty collecting data from a profession in such diverse bases, and referrals were over one year in a medium sized city (and hence not insignificant).

Bean's (1980) research criticised GPs for inappropriate referrals and a failure even to be minimally aware of the law. This study indicates that GPs, overall, distinguished between those referred for compulsory admission and those for other specialist help, indicating a number of factors triggering section referrals. The two groups differed markedly in the severity of their condition. A greater proportion of section referrals were considered by specialist practitioners to be definite cases, there was greater emphasis on psychotic conditions, primarily schizophrenia and affective psychosis, while the majority of referrals were previously known to the psychiatric services. This suggests that a history of psychiatric disorder may have played a part in the decision to refer for compulsory admission. Together these indicate three key characteristics acting as a trigger for GP referral for section assessment: definite disorder, psychotic condition, and previous contact with psychiatric services. The emphasis, therefore, tends not to be on acute conditions of recent onset, and it may be that previous specialist diagnosis, together with a previous willingness by specialists to see the patient, encourages GPs to make a section referral.

While the predominance of psychotic primary problems demonstrates their centrality, significantly more relationship problems were evident in section referrals. These are likely to reflect problematic behaviour by individuals referred. Psychotic condition on its own was often insufficient to trigger referral. A fourth trigger was frequently when problematic behaviour occurred in a familial or wider social context. A final trigger appears to be the sex of the individual. This is of some concern. GPs may be more willing to use the compulsory route for women than for men. Finally, the brevity of intervention with section referrals, whether or not they were compulsorily admitted, indicates a 'mental set' on the part of specialist practitioners, which involves seeing the task simply as one of section assessment separate from other forms of help. This suggests that if GPs wish to keep their options open, incorporating the possibility both of hospital admission and other intervention, it may be better not to refer for a section.

\section{References (See end of paper II.)}

\title{
General practitioners' referrals for compulsory admission under the Mental Health Act, II: the process of assessment
}

\section{Michael SHEPPARD}

This is the second of two articles on GP referrals for compulsory admission, and seeks to examine the process and outcome of assessment by (a) comparing
GP with other section assessment referrals and (b) comparing GP referrals who were compulsorily admitted to hospital with those not compulsorily 
admitted or voluntarily admitted. In relation to the law the main relevant sections for this article are sections 2,3 and 4. There are two basic grounds for admission: that the patient is suffering from a mental disorder and that admission is in the interests of his/her own health or safety or for the protection of others. Section 4 requires one and sections 2 and 3 , two medical recommendations, as well as an application by an approved social worker (ASW) or nearest relative. Section 2, admission for assessment, involves admission for up to 28 days; section 4, emergency admission for assessment, involves admission for up to 72 hours; and section 3, admission for treatment, allows admission for up to six months, and is renewable.

\section{The study}

In addition to the instrument discussed in the previous article, a brief instrument was used to focus on specific factors in the section assessment. In relation to the assessment process, the approved social worker (ASW) was asked to indicate, from a detailed list, which members of the patient's social circle were interviewed as part of the assessment process. They also indicated which social factors they considered in the assessment, derived from factors indicated in the DHSS (1983) memorandum as necessary to "interview in a suitable manner" (section 13). Finally, the ASW indicated the section under which the patient was admitted, or whether informal or no admission took place. This was completed by the ASW following medical consultation.

\section{Findings}

\section{GP and other referrals}

Forty referrals for compulsory admission, a third of all referrals, were made by GPs during the study year. Of the other referrals, 17 were by the family, 13 by psychiatrists, 17 other health professionals, 15 police, nine social work and nine other referrals. Although just over half both groups were aged under 44 , there were marked differences in other respects. Eighty per cent of GP and $54 \%$ of other referrals were women $(P=0.0009) ; 18 \%$ of GP and $5 \%$ of other referrals had children, compared with $35 \%$ of households in the general population; $35 \%$ of GP and $59 \%$ of other referrals received state benefit other than pension or child benefit, universally available to relevant groups; and $46 \%$ of GP and $29 \%$ of other referrals were cohabiting or married (compared with $65 \%$ of the general population who were married). Both groups differed from the general population, but other referrals were particularly materially deprived.
Outcome was also quite different. Significantly fewer GP referrals ( $43 \%$ ) were subsequently compulsorily admitted than other referrals $(66 \%)(P=0.02)$; $30 \%$ of GP referrals were informally admitted and $28 \%$ not admitted at all, compared with respectively, 15 and $19 \%$ of other referrals. This is interesting, because it indicates, with the benefit of hindsight provided by specialist assessment, that it was more frequently unnecessary for GPs than other referrals to pursue the compulsory route, despite the fact that other referral sources were frequently non-medical. Exactly the same proportion of each group, $85 \%$, were considered by the specialists to be 'definite' cases. Specialists also indicated, from the range of mental health and social problems, which they considered to be primary: in $80 \%$ of GP and $82 \%$ of other referrals, mental health problems were considered primary. GP referrals averaged slightly more social problems: 2.1 compared with 1.8 , although, with the exception of child care problems, present in $18 \%$ of GP and $5 \%$ of other referrals, there were no noticeable differences in the nature of social problems. ASWs indicated social factors considered in their assessment, which numbered eight in all and were derived from those recommended in DHSS (1983) guidelines. There was only one significant difference: family relations and support were considered in all GP referrals and $88 \%$ of other referrals $(P=0.05)$. Although not significant, there was markedly greater emphasis on non-familial social relations and support and financial/material circumstances in other referrals, consistent with the material and marital status of each group.

\section{Outcome of GP referrals}

Outcome, comparing GP section referrals with those not compulsorily admitted and those admitted to hospital with those not so admitted, showed women were less frequently compulsorily admitted and more frequently informally admitted than men, that compulsorily admitted patients tended to be single, although many married patients were informally admitted. While significantly fewer compulsorily admitted patients had children, most of those with children were informally admitted to hospital.

Significantly more of those admitted to hospital $(97 \%)$ than of other patients $(55 \%)$ were considered definite cases $(P=0.003)$, as were markedly more compulsorily (94\% of admitted patients) than patients not compulsorily admitted $(78 \%)$. However 18 of the 34 definite cases were not compulsorily admitted and six were not admitted at all. Fifteen of the 27 psychotic patients were compulsorily admitted and 22 in all were admitted to hospital. Psychotic state did not therefore automatically lead to admission, although almost all (15 out of 17) compulsorily admitted patients were psychotic. With 
only one exception, there were no marked differences between those compulsorily admitted and those not, and patients admitted to hospital and those not admitted in relation to social problems. The exception was child care, a problem suffered by seven patients, none of whom were compulsorily admitted although four were admitted to hospital. Interestingly, the average number of social problems suffered by compulsorily admitted patients (1.82) was markedly less than those not (2.56) and slightly less (2.13) for patients admitted to hospital than not admitted to hospital (2.36)

\section{Comment}

Both groups diverged greatly from the general population, were more likely to be materially disadvantaged, and less likely to have the support of a relationship with a spouse or cohabitee. As they were overwhelmingly identified as definite cases, psychiatric state indicates they were in terms of mental health generally appropriate referrals.

However, GP referrals were significantly more frequently informally admitted or not admitted at all: other referrers, although frequently lay, were more successful in referring individuals requiring compulsory (as opposed to informal) admission. One possibility is that GPs were less able to distinguish between the need for treatment and the need for compulsory treatment. This is a matter of concern because actions involving compulsion raise issues of civil rights. The Act takes these rights seriously (see e.g. sections 131 and 139), and in many cases the GPs may not have adequately explored the possibility of informal admission or the appropriateness of compulsion. Certainly the centre offered a quick response service, in which patients would be seen the same day, so GPs did not need to request a section in order to get a quick response. Indeed, often with previous acquaintance with the patient, the GP will frequently have been in a better position to persuade them to enter hospital informally. There is, then, some evidence of GPs being 'trigger happy' - of being rather too quick to pursue a route involving possible compulsion rather than alternatives.

This is most serious for women. While women predominated in GP referrals, they were less frequently compulsorily admitted, and had a greater tendency to informal admission. Other referrals by GPs, noted in the previous article, did not show this excess of women. This tendency by GPs to pursue a compulsory route with women is of some concern.

The fact that not all mentally ill, and particularly psychotic, patients were compulsorily admitted or even admitted to hospital informally emphasises the importance of factors other than mental illness in the assessment: the health or safety of the patient or protection of other persons. However, on average, fewer social problems were identified among compulsorily admitted patients: taken with primary problems this indicates sections occurred when, among other things, problems were more unequivocally psychiatric. The greater availability of partners and less material deprivation suggests GP referrals had better support networks than other referrals. Indeed ASWs more frequently interviewed spouses and assessed family supports with GP referrals and made more contacts with members of the patient's social network. The greater number of social problems in GP referrals suggests that, relative to other referrals, they played a more important part in the decision by GPs to refer. These clues suggest that, while aware of the negative elements of social problems, GPs may often have underestimated the positive influence of social networks, either by persuading the patient to enter hospital, or providing sufficient support in the community.

Overall, these data suggest an amendment to the generally positive findings in the previous article (above). First, the absence of social supports as well as the presence of psychotic disorder appear important in the decision to use compulsion. Second, GPs should be aware that they may unnecessarily be pursuing a compulsory route. This is, third, particularly the case for women. Fourth, they may give insufficient weight to the potentially positive influence of social support. The tendency for other, frequently lay, referrers to identify more accurately those subsequently requiring compulsion does appear of some concern.

\section{Note}

Patients admitted to hospital included those informally admitted as well as compulsorily admitted.

\section{References}

BARNes, M., Bowl, R. \& Fisher, M. (1990) Sectioned: Social Services and the Mental Health Act. London: Routledge.

Bean, P. (1980) Compulsory Admissions to Mental Hospitals. London. John Wiley.

DHSS (1983) Memorandum on the Mental Health Act 1983. London: HMSO.

Rogers, A. (1989) Psychiatric referrals from the Police. Unpublished PhD thesis. University of Nottingham.

SHEPPARD, M. (1990) Mental Health: The Role of the Approved Social Worker. Sheffield. JUSSR. University of Sheffield Press.

- (1991) Mental Health Work in the Community: Theory and Practice in Social Work and Community Psychiatric Nursing. London: Falmer.

WHO (1977) Manual of the International Statistical Classification of Diseases, Injuries and Causes of Death. Ninth Revision. London: HMSO. 